\title{
Casa de citas. José Martí, Oscar Wilde y el renacimiento de la fotografía de autor
}

Javier Guerrero

Princeton University

\begin{abstract}
Resumo
O artigo reexamina duas crónicas de Jose Martí nas quais o intelectual cubano discute a chegada e a primeira apresentação pública do Oscar Wilde, em Nova York. A proposta de leitura suspeita sobre essas crônicas e propõe ler criticamente os modos em que Martí cita sem saber ao excêntrico dândi irlandês. $\mathrm{O}$ artigo lê a primeira crónica de Martí sobre Wilde, aquela aparecida em Caracas em 21 de janeiro de 1882, como um dispositivo que percebe o surgimento da fotografia de autor. Além disso, propõe-se que as fotografias de Wilde tiradas em New York, e as controvérsias que as cercaram, constituem um renascimento da fotografia de autor que serve como veículo auto figurativo e ensaio de autonomia material para uma nova espécie de escritor na América Latina.

Palavras chave: fotografia de autor; Oscar Wilde; José Martí; pose; escritores gay; dândi; 1882 .
\end{abstract}

\section{Resumen}

El artículo reexamina dos crónicas de José Martí en las que el intelectual cubano discute el arribo y primera presentación pública de Oscar Wilde en Nueva York. La propuesta de lectura sospecha sobre estas crónicas y propone leer críticamente las maneras en las que Martí cita a ciegas al excéntrico dandi irlandés. El artículo lee la primera crónica de Martí sobre Wilde, aquella aparecida en Caracas el 21 de enero de 1882, como un artefacto que da cuenta de la emergencia de la fotografía de autor. Asimismo, propone cómo las fotografías que Wilde se toma en Nueva York y las polémicas que las rodean constituyen un renacimiento de la fotografía de autor que sirve como vehículo autofigurativo y ensayo de autonomía material para una nueva especie de escritor en América Latina.

Palabras clave: Fotografía de autor; Oscar Wilde; José Martí; pose; escritores gay; dandi; 1882. 
1. MORRIS, Roy Jr. Declaring His Genius: Oscar Wilde in North America, 2013, p. 3.

2. HOFER, Matthew, Gary Scharnhorst (eds). Oscar Wilde in America: The Interviews, 2010, p. 4.

3. MARTÍ, José. "Oscar Wilde". La Opinión Nacional, 1882, p. 1.
El 2 de enero de 1882, Oscar Wilde llega al puerto de Nueva York a bordo del vapor Arizona para iniciar una gira que lo llevará a varias ciudades de Estados Unidos y Canadá. De este viaje proviene su muy citada aunque nunca confirmada frase ante la pregunta de rutina de un funcionario de aduana: "No tengo nada que declarar más que mi genio". Wilde llega a Nueva York y en el continente dicta más de 140 charlas en 260 días $^{1}$ y concede casi un centenar de entrevistas ${ }^{2}$. Pero es en la noche del 9 de enero de 1882 cuando oficialmente el poeta irlandés inicia su gira con una charla titulada "El renacimiento inglés del arte" en el Chickering Hall de Nueva York. A esta cita, repleta de curiosos y demás interesados en ver al aún joven e inexperto Oscar Wilde, acude como corresponsal el poeta e intelectual cubano José Martí. Un mes después, el 11 de febrero, Martí publica la muy citada crónica del encuentro en la que describe con abundantes detalles la seductora y muy estudiada apariencia del dandi irlandés:

Ved a Oscar Wilde! No viste como todos vestimos, sino de singular manera. Ya anuncia su traje el defecto de su propaganda, que no es tanto crear lo nuevo, de lo que no se siente capaz, como resucitar lo antiguo. El cabello le cuelga cual el de los caballeros de Elizabeth de Inglaterra, sobre el cuello y los hombros; el abundoso cabello, partido por esmerada raya hacia la mitad de la frente. Lleva frac negro, chaleco de seda blanco, calzón corto y holgado, medias largas de seda negra, y zapatos de hebilla. El cuello de su camisa es bajo, como el de Byron, sujeto por caudalosa corbata de seda blanca, anudada con abandono. En la resplandeciente pechera luce un botón de brillantes, y del chaleco le cuelga una artística leopoldina. Qué es preciso vestir bellamente, y él se da como ejemplo. Solo que el arte exige en todas sus obras unidad de tiempo, y hiere los ojos ver a un galán gastar chupilla de esta época, y pantalones de la pasada, y cabello a lo Cromwell, y leontinas a lo petimetre de comienzos de siglo ${ }^{3}$.

En su influyente ensayo "La política de la pose", Sylvia Molloy parte de la profunda impresión que la apariencia de Oscar Wilde genera en José Martí. De acuerdo con Molloy, la extravagancia de Oscar Wilde parece producir en el intelectual cubano un sentimiento tanto de perturbación como de inesperada fascinación. Molloy cita largamente la crónica de Martí, en especial parte del pasaje que acabo de reproducir para entonces llamar la atención sobre una de las afirmaciones: "No viste como todos vestimos, sino de singular manera". Molloy se pregunta a quiénes se refiere el nosotros evocado por Martí o más bien qué de ese nosotros parece inquietar la imagen 
de Oscar Wilde. Es a partir de estas preguntas que la autora encuentra el punto de partida para toda una reflexión crítica en torno a la pose y su capacidad transgresora, reflexión que no se queda allí sino que perpetra una relectura radical del fin de siècle hispanoamericano. Esto se confirma con contundencia cuando en la introducción de su libro Poses de fin de siglo. Desbordes del género en la modernidad, que recoge toda su reflexión sobre el género y la sexualidad en un contexto hispanoamericano de entresiglo, Sylvia Molloy cite una serie de escenas como figuras indispensable para pensar su tecnología crítica y, por lo tanto, su radical relectura del campo. Y la lista naturalmente comienza con la descripción de Martí - un Oscar Wilde vestido de terciopelo en el Chickering Hall de Nueva York- y continúa con una colección de escenas no menos interesante: una caricatura de José Ingenieros perversamente "italianizado", una foto de Teresa de la Parra y Lydia Cabrera en París paseando un perrito, el Próspero de José Rodó acariciando la estatua de Ariel, el dibujo de un corazón ahuecado en una carta de Delmira Agustini al hombre que la mataría, la imagen del perro muerto de Tolstoi imaginada por Rubén Darío, una fotografía de las manos de Amado Nervo -aunque me parece que Molloy quiere referirse a las manos enjoyadas de Salvador Novo- y otra de Rosita de la Plata, el inmigrante español travestido ${ }^{4}$. Toda la lista, todas las escenas que presenta Sylvia Molloy para poner en perspectiva el fin de siglo hispanoamericano apelan a la vista: todas parecen estar mediadas y medidas por los ojos.

En este artículo quiero reexaminar la citada crónica de José Martí o, más bien, girar la atención sobre otra crónica de publicación previa que escribe Martí a propósito de la llegada de Oscar Wilde a los Estados Unidos y que ha pasado desapercibida para la crítica. Me detendré en la relación entre mirada, cuerpo y visualidad para entonces pensar ya no en el acto de posar sino en la emergencia de la fotografía y de su relación con la noción de autor. Tal emergencia fotográfica parece coincidir con la llegada de Wilde a Nueva York pero sobre todo me interesa inscribirla a propósito de cierta reflexión y hasta intuición crítica que encuentro en las crónicas de José Martí. El poeta y cronista cubano parece sugerir la posibilidad de que la fotografía de autor constituya una nueva funda de piel, una piel luminosa para aquellos que desean mostrarla, para aquellos que no se visten como nosotros. En este sentido, insisto en repensar la cita que hace Martí de Wilde, al construir una imagen a la vez irresistible y perturbadora para por lo tanto proponer cómo la fotografía de Oscar Wilde se vuelve una especie de vehículo visual sobre el que se calca una nueva especie de escritor en América Latina. Quiero reinscribir estas crónicas en los debates contemporáneos acerca del cuerpo y la visualidad y entender cómo Martí parece anticipar lo que podría nombrase como un renacimiento de la
4. MOLLOY, Sylvia. Poses de fin de siglo. Desbordes del género en la modernidad, 2012, p. 12. 
fotografía de autor y en cierto sentido pensar la política de la piel luminosa que la fotografía concede a estas sensibilidades sexuales finiseculares. Tal como expondré a lo largo de este artículo, la consecuente materialidad que parece cobrar la fotografía de autor tiene la capacidad no solo de desplazar las poses como ficciones engañosas, falsificaciones que encubren el original y por lo tanto, el origen del sexo, sino también proponer cómo se constituye esta nueva funda de piel a la que se enfrenta la compleja y densa hijuria de ver.

\section{La cita de Martí}

5. En las notas finales a la edición crítica de las obras completa de José Martí se apunta que en la primera edición de las obras, Gonzalo de Quesada y Aróstegui incluyó su crónica titulada "Oscar Wilde" en el tomo 13 y dio como fuente de publicación $\mathrm{El}$ Almendares, de enero de 1882 , sin precisar la fecha exacta: "De este diario habanero solo se han localizado ejemplares de entre julio y noviembre de 1882, en uno de los cuales se reprodujo el artículo de Martí sobre Darwin tomado de La Opinión Nacional, de Caracas, incluido en el tomo 10 de esta serie. Durante la preparación del presente tomo se encontró este escrito sobre Wilde en la edición del diario caraqueño correspondiente al 12 de febrero de 1882, fecha que ha sido la guía para su ubicación cronológica dentro del tomo y cuyo texto se ha seguido en esta edición, por ser la primera fuente a nuestro alcance, en cuanto a fecha de publicación". MARTÍ, José. Obras completas: (edición crítica) Tomo9 (1881-1882) Estados Unidos, 2000, p. 387.
Como ya mencioné, comienzo este artículo reexaminando la crónica de José Martí sobre Oscar Wilde, pieza sobre la que han propuesto nuevos giros críticos -como el ya planteado por Sylvia Molloy- acerca de la visualidad y la figura de autor. Coloco todo bajo sospecha y comienzo dando cuenta de la imprecisión acerca de la fecha de publicación de este artículo así como de su reimpresión. Si bien Molloy no hace referencia a fecha alguna sino a su publicación en La Nación de Buenos Aires de la conocida crónica de Martí, han sido varios los críticos que han señalado que la publicación original se produce en la revista Almendares de La Habana. A propósito de esto, afirmo que esta crónica forma parte de las Cartas de Nueva York que Martí escribe expresamente para el periódico La Opinión Nacional de Caracas. La crónica sobre Oscar Wilde aparece por primera vez y como ya mencioné, especialmente escrita para el vespertino venezolano, el 11 de febrero de 1882 para luego republicarse en los diarios La América de Madrid el 8 de noviembre de 1882 y La Nación de Buenos Aires el 10 de diciembre del mismo año. Aunque no ha habido evidencia, en todo caso, la publicación en la revista cubana Almendares sería posterior a su publicación en el diario venezolano ${ }^{5}$. Me detengo en este detalle no solo para aclarar la circulación del texto de Martí y, por lo tanto, la de Oscar Wilde por Iberoamérica sino principalmente para dar cuenta o leer ciertas imprecisiones que podrían tornarse ilegibles de no llamarse la atención sobre ellas. Por lo tanto, quiero indagar en aquellos elementos que puede ofrecer otras posibilidades de lectura y, a raíz de esto, diversas consecuencias críticas.

Justamente, me interesa sospechar del relato de Martí. Más que esto e incluso, más allá de la indiscutible visualidad y teatralidad que le ofrece a la crónica, enfatizando lo que aparentemente ven sus ojos, me interesa sospechar sobre su construcción. Mi duda se basa en que la descripción hecha por Martí parece seguir la descripción de ciertas crónicas periodísticas 
y artefactos visuales que aparecen en diarios y revistas locales y circulan a propósito de la primera presentación de Wilde en Estados Unidos. La crónica que hace, por ejemplo, el New York Times afirma: "His long and bushy hair crowded in front of his ears and nearly to his eyes, but it was brushed well off his forehead. He wore a low-necked shirt with a turned-down collar and large white necktie, a black claw-hammer coat and white vest, knee-breeches, long black stockings, and low shows with bows". La descripción sorpresivamente coincide con la de Martí. Por supuesto, podría argumentarse que la coincidencia se debe a la simple razón de que ambos cronistas hayan asistido al mismo encuentro y visto a un solo Oscar Wilde.

No obstante, de la larga crónica de Martí, llama la atención la ausencia de detalles acerca de la movilidad de Wilde en el escenario, sus gestos o ademanes, que abundan en otros relatos periodísticos. La ya citada crónica del New York Times afirma "He wore white kid globes, and when he placed his hands upon the stand in front of him, rested one of his feet on the base of the stand...”’ Y Y más aún, a pesar de dar la impresión de haber acudido al Chickering Hall y de hacer referencia de que se trata de una "casa de anchos salones, donde en Nueva York acude el público a oír lecturas", Martí no dice nada acerca de la voz de Wilde cuando casi todas las crónicas llaman la atención sobre este aspecto. Los muchos artículos publicados insisten en la voz de Wilde como sepulcral (sepulchral), fantasmagórica?, monótona, voz que podría provenir de la ultratumba ${ }^{10}$, de tonos desagradables ${ }^{11}$. El énfasis por parte de los diarios a propósito de la disonancia de Wilde, así como en torno a su inseguridad ante lo que sería la primera presentación pública de su carrera, están totalmente ausentes de la crónica de Martí. Pero quiero llamar la atención acerca de algo más. Encuentro una importante semejanza entre la descripción del escenario con la ilustración de la conferencia de Wilde en Nueva York aparecida en The National Police Gazette el 28 de enero de1882 (Fig. 1). El comienzo de la descripción que hace Martí del dandi -es decir, lo que antecede a su descripción de Wilde- da cuenta de una escenografía. Martí escribe: "Una silla vacía, de alto espaldar y gruesos brazos, como nuestras sillas de coro, espera al poeta. De madera oscura es la silla, y de marroquí oscuro su respaldo y su asiento. De castaño más suave es el lienzo que ocupa la pared del fondo. Junto a la silla una mesa elegante sostiene una artística jarra, en que brilla, como luz presa, el agua pura"12. La detallada descripción precede la aclamación de ver a Oscar Wilde, la cual parece funcionar a un nivel narrativo como expectativa de su aparición disruptiva y fascinante.
6. "Oscar Wilde's Lecture: A Large Audience Listens to the Young Aesthete." The New York Times, 1882 , p. 5.

\section{Ibídem.}

8. MARTÍ, José. "Oscar Wilde". La Opinión Nacional, 1882, p. 1.

9. "Chickering Hall was filled on the night of Jan. 9, when Oscar Wilde made his first public appearance in this country, under the auspices of D'Oyly Carte, as represented in this matter by Col. Morse. The tall and tender aesthete talked like a ghost, but still intelligently and intelligibly, about poetry and criticism". "City Summary". New York. Clipper, 14/01/1882, p. 710.

10. "He began to speak in a voice that might have come from the tomb. "Oscar Wilde's Lecture: A Large Audience Listens to the Young Aesthete." The New York. Times, 1882, p. 5.

11. "His tones are not grateful, but his ideas are to many people". "City Summary". New York Clipper, 14/01/1882, p. 710.

12. MARTÍ, José. "Oscar Wilde”. La Opinión Nacional, 1882, p. 1. 


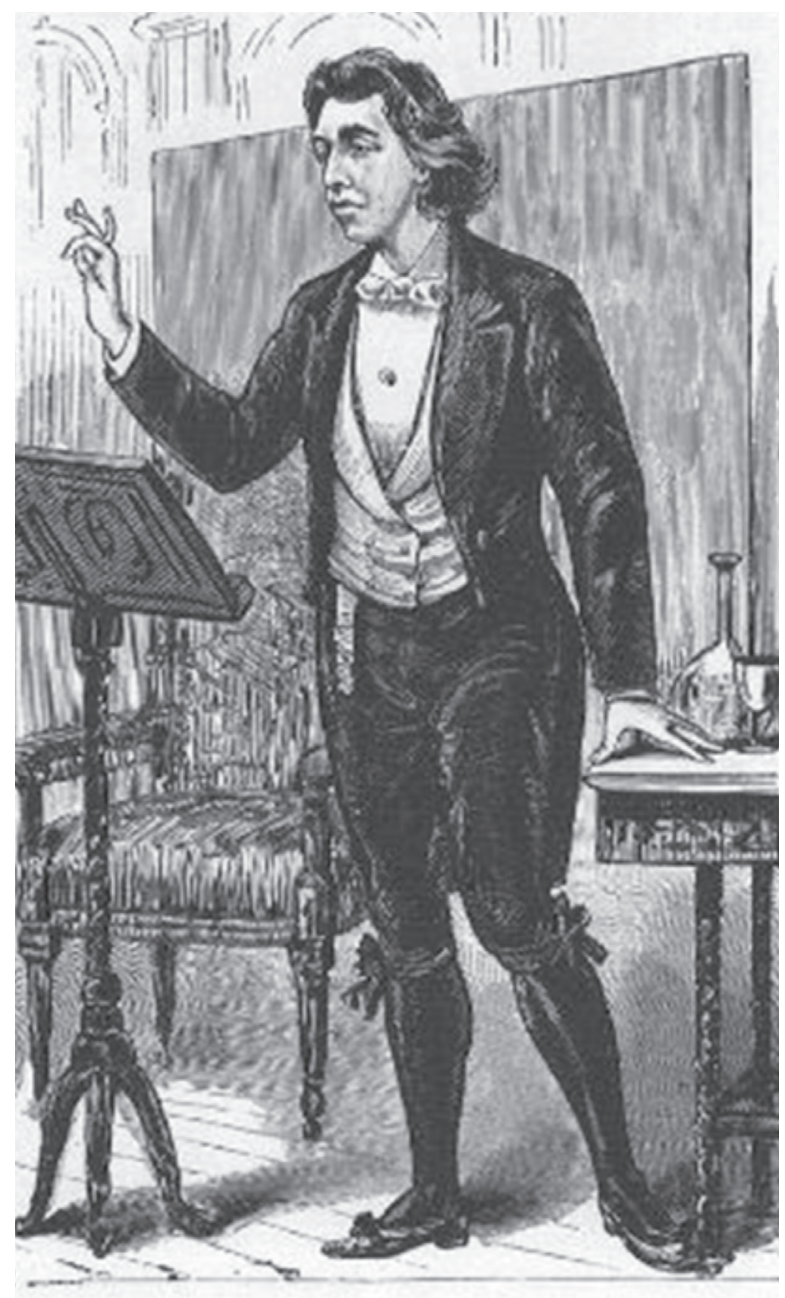

OSCAR WHDK ON THE PLATFORM.

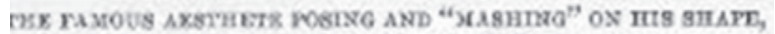

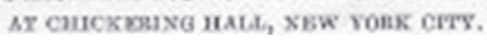

Fig. 1. "Oscar Wilde on the Platform. The Famous Aesthete Posing and 'Mashing' on His Shape at Chikering Hall, New York City." The National Police Gazette. New York, 28 de enero de 1882, p. 4.

Todos los elementos de esta ilustración, tanto el atuendo de Wilde como la escenografía -la silla vacía de alto espaldar, el lienzo que ocupa la pared del fondo y la mesa que sostiene la jarra de agua- son los únicos detalles que José Martí parece describir de la escena, en especial del amplísimo y muy ornamentado salón de Nueva York, abarrotado para la ocasión de un público deseoso de oír pero sobre todo ver al apóstol del estetismo. Asimismo, llama la atención que Martí se refiera a una sola silla cuando las crónicas periodísticas dan cuenta de que son dos, una para Wilde y otra para Colonel Morse. ${ }^{13}$ Incluso, Sylvia Molloy, tras afirmar que Martí acude al encuentro, plantea cierto desbalance entre el público y el cronista y, para ello, recrea la escena en cuestión: "Perdido entre el público neoyorquino, Martí, el anónimo corresponsal extranjero, contempla, mejor
13. "Two chairs had been place a few feet from the lecturer's stand". "Oscar Wilde's Lecture: A Large Audience Listens to the Young Aesthete." The New York Times, 1882 , p. 5. 
aún, espía a Wilde, absorbiendo cuidadosamente al hombre y sus palabras, para mejor relatar su experiencia a los lectores hispanoamericanos de La Nación"14. Entonces me pregunto: ¿realmente asistió Martí a la presentación de Oscar Wilde en el Chickering Hall de Nueva York?, ¿vio José Martí en persona a Oscar Wilde? No intento desautorizar la crónica de Martí, ni poner bajo sospecha su relevancia, ni tampoco afirmar que el relato que Mariano Siskind considera como el primer discurso latinoamericano acerca de la literatura mundial, en el que por primera vez parece ponerse énfasis en la universalidad de la literatura y en los posibles efectos emancipatorios para el corpus literario americano ${ }^{15}$, esté basado en una puesta en escena a propósito de las descripciones de prensa e ilustraciones -lo cual, incluso, me parece que añadiría otras capas de cosmopolitismo al artefacto. Por el contrario, me interesa proponer las posibles mediaciones visuales que implica la noción de autor. Quiero dirigir la atención a la manera en que José Martí cita a Oscar Wilde, para entonces dar cuenta de lo que podría llamar ya no la política de la pose, sino la política de la cita. Y si como ya parece entender Molloy en la introducción a su Poses de fin de siglo, todo pasa por los ojos, en esta ocasión ocurre de manera doble, todo pasa por los ojos de José Martí cuando ve dibujado a Oscar Wilde.

Es aquí donde quiero proponer un giro crítico y direccionar la mirada a otra crónica sobre Wilde que de manera previa, y a propósito del arribo del escritor al puerto de Nueva York, Martí publica el 21 de enero de 1882 en el vespertino caraqueño La Opinión Nacional. En este diario aparecen sus crónicas en primera página y Martí colabora con regularidad de manera exclusiva las cartas de Nueva York, llevan el subtítulo de "Expresamente escritas para La Opinión Nacional'- e incluso, de manera anónima, el intelectual cubano redacta una columna titulada "Sección Constante" para el mismo periódico venezolano ${ }^{16}$. Como afirmé, la crónica forma parte de las Cartas de Nueva York en las que Martí aborda varios temas de actualidad, entre ellos (coincidiendo con la visita de Wilde a Estados Unidos), el muy sonado proceso del magnicida Charles Guiteau. Pero la descripción del cuerpo de Wilde, una vez más, parece coronar el relato. José Martí escribe:

Con los primeros días del año, llegó a Nueva York, a bordo de uno de esos vapores babilónicos que parecen casas reales sobre el mar, un hombre joven y fornido, de elegante apostura, de enérgico rostro, de abundante cabello castaño, que se escapa de su gorra de piel sobre el Ulster recio que ampara del frío su robusto cuerpo. Tiene los ojos azules, como dando idea del cielo que ama, y lleva corbata azul, sin ver que no está bien en las corbatas el color que está bien en los ojos. Son nuestros tiempos de corbata negra. Este
14. MOLLOY, Sylvia. Poses de fin de siglo. Desbordes del género en la modernidad, 2012, p. 18.

15. SISKIND, Mariano. Cosmopolitan Desires: Global Modernity and World Literature in Latin America, 2014, p. 109.

16. De acuerdo con Gregory

Zambrano, entre el 4 de noviembre de 1881 y el 15 de junio de 1882, en $L a$ Opinión Nacional de Caracas se publicaron 112 artículos de José Martí bajo la denominación común de "Sección constante". ZAMBRANO, Gregory. "La Sección constante de José Martí. Pequeño tratado de enciclopedia”. Revista Investigación, 2004, p. 56. 
17. MARTÍ, José. “El proceso de Guiteau. El estetismo. ¡Pálido Postlethwaite! El poeta Oscar Wilde. Los inmigrantes. Un grande anciano muerto". La Opinión Nacional, 1882, p. 1.
18. Ibídem. joven lampiño, cuyo maxilar inferior, en señal de fuerza de voluntad, sobresale vigorosamente-es Oscar Wilde, el poeta joven de Inglaterra, el burlado y loado apóstol del Estetismo $^{17}$.

El comienzo coincide con el estilo de la crónica ya leída: la aparición de Oscar Wilde precedido de una descripción que genera expectativa. Una vez más, Martí destaca la apariencia de Oscar Wilde, su muy excéntrica pero también estudiada apariencia (la corbata azul a juego con sus ojos). Sin embargo, de este comienzo quiero resaltar dos elementos. Por un lado, la frase que desaprueba, la que proscribe el uso de la corbata azul "no está bien" y que pontifica: "Son nuestros tiempos de corbata negra". Como lo hiciera Molloy, me pregunto: ¿a qué tiempos se refiere Martí? Quiero llamar la atención sobre el gesto tautológico que entonces produce la segunda crónica de Martí, la de la presentación de Wilde en el Chickering Hall, la cual enfatiza la diferencia en el vestir. Una vez más, la elección de una prenda del atuendo de Wilde parece funcionar para cifrar el secreto a voces. Por otro lado, y aún más importante aquí, resulta la oración con la que Martí cierra el pasaje en el que finalmente devela la identidad de la figura descrita: "es Oscar Wilde, el poeta joven de Inglaterra, el burlado y loado apóstol del estetismo". De este final, entonces, destacaré y me centraré en la idea del poeta "burlado". Martí continúa su crónica y explica a lo que se refiere: “¿Quién no ha visto ese cuaderno de caricaturas que se publica cada semana en Londres, y en cuya carátula ríe maliciosamente, cercado de trasgos, bichos y duendes, un viejillo vestido de polichinela?"18. Martí se refiere a los ilustradores y tabloides, que en Inglaterra hacen del cuerpo de Wilde -de sus manierismos e indumentaria- toda una parodia:

Londres ríe hace meses con el poeta Postlethwaite, que es el nombre, ya famoso de un lado y otro del Atlántico, que el Punch ha dado a Oscar Wilde. Postlethwaite es una lánguida persona, que abomina la vida, como cosa democrática, y pide a la luz su gama de colores, a las ondas su escala de sonidos, a la tierra apariencia y hazañas celestiales. Todo disgusta al descontentadizo Postlethwaite. Cuanto hacen los hombres, le parece cosa ruin. De puro desdeñar los hábitos humanos, va tan delgado que parece céfiro. Postlethwaite quiere que sea toda la tierra un acorde de armoniosa lira. Estos paramentos de los hombres de ahora le mueven a desdén, y quiere para la vida empleo espiritual, y para los vestidos colores tenues y análogos, de modo que el fieltro del sombrero no desdiga del cuero de las botas, y sea todo melancólico azul, o pálido verde. Postlethwaite es ya persona célebre, y toda Inglaterra y todos los Estados Unidos aplauden hoy una ópera bufa de un poeta inglés en que se cuentan los melodiosos y alados amores del tenue bardo mustio ${ }^{19}$.

No obstante, lo que quiero enfatizar aquí viene de manera inmediata. Martí enseguida escribe: "Con tanta saña movió 
Du Maurier su lápiz tajante, que cuando publicó al cabo Oscar Wilde... su volumen de versos, no veían los lectores en sus arrogantes y límpidas estrofas más que aquella ridícula figura, que pasea con aire absorto por la tierra su mano alzada al cielo, como coloquiando con las brisas, y su nariz husmeante, en que cabalgan colosales gafas. Ahí está, en luz y sombra, el movimiento estético"20. Si bien es cierto que pese a su fascinación por el look de Wilde, Martí parece encontrar en su atuendo, gestualidad y maneras la falsificación propia de la apariencia - produciendo en este sentido, una separación entre performance y obra-, el intelectual cubano también protesta por la caricaturización que los medios impresos ingleses y, de manera consecuente, los de Estados Unidos hacen de Wilde. Por lo tanto, Martí comprende cómo toda esta iconografía fóbica sella la obra del escritor y, de manera más importante, usurpa su cuerpo. En cierto sentido, aunque Martí entiende, entiende que la caricaturización de la figura de Wilde está basada en su apariencia, la cual también desaprueba, esta operación lo encadena a unas manos, como las de Du Maurier, que portan el lápiz tajante para trazar las ponzoñosas y estrechas intenciones de la prensa y la opinión pública. Entonces, ¿qué parece estar proponiendo Martí?, ¿qué posibilidades les quedan a estos escritores que no se visten como nosotros, que se rebelan a los tiempos de corbata negra? Yendo incluso más allá de las intenciones del cronista, ¿a qué apunta esta nueva crónica frente al control fóbico de la visualidad que parece ocupar el cuerpo de Oscar Wilde?

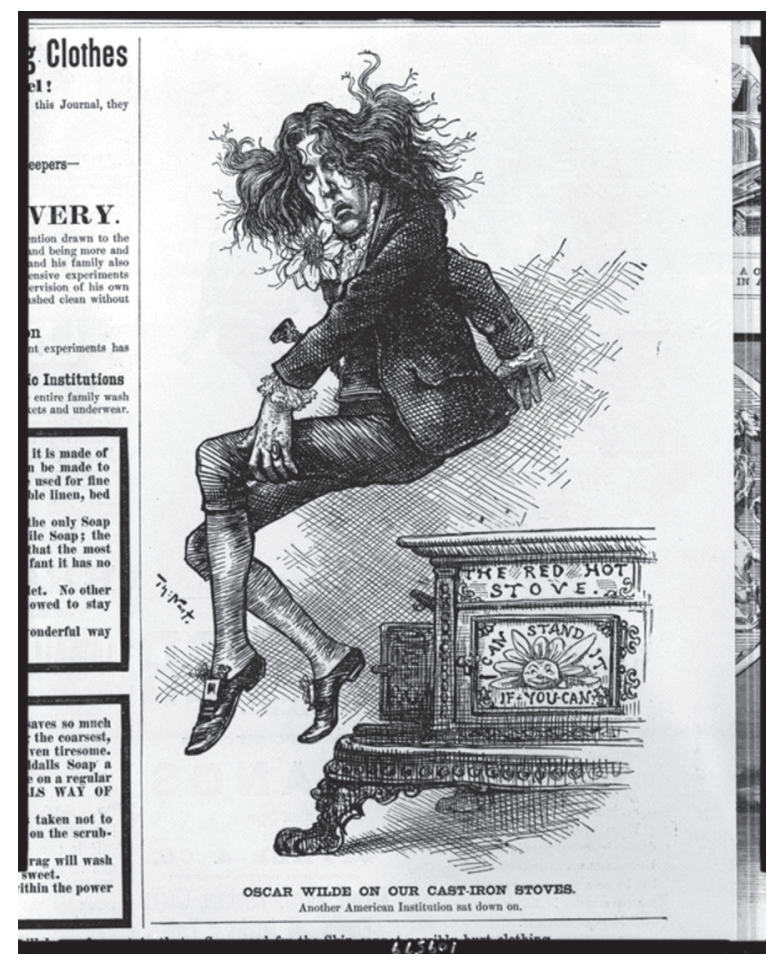

Fig. 2. Thomas Nast, "Oscar Wilde on Our Cast-Iron Stover. Another American Institution sat down on”. Harper's Weekly, 9 de septiembre de 1882, p. 575. Library of Congress.
20. Ibídem. 


\section{La cita de Wilde}

21. De acuerdo con su correspondencia, los primeros días en Estados Unidos están repletos de encuentros, cenas. Sus cartas son cortas y principalmente funcionan para organizar una muy abultada agenda social. Wilde cuadra horas o se excusa al no poder concurrir a alguna invitación y en ocasiones, agenda hasta dos cenas un mismo día.
En los últimos años, ha habido un importante resurgimiento crítico de Oscar Wilde, en especial, en lo que implica su presencia en los Estados Unidos. Una documentadísima bibliografía ha intentado dar cuenta de varias perspectivas, mas ha prevalecido la indagación en el nacimiento del concepto moderno de autor e incluso, el de celebridad.

La llegada de Oscar Wilde a Estados Unidos se produce mediada por su imagen, imagen que de manera paradójica está en ausencia. Es decir, pese el elevado interés en cómo luce Oscar Wilde, su llegada no viene acompañada de fotografías. En un principio, la prensa estadounidense no parece acudir a las ilustraciones. En casi todos los artículos acerca del arribo del poeta irlandés a Nueva York hay una imperiosa necesidad de trasponer lo que ven los ojos de los cronistas. Las ilustraciones aparecerán más tarde durante la gira de Oscar Wilde por Norteamérica y, como ya decía Martí, reproducen la caricaturización operada por los tabloides ingleses (Fig. 2). Sin embargo, el vacío fotográfico será algo del todo provisional.

A solo dos días de arribar a Nueva York, Oscar Wilde ya tiene una cita a la que debe acudir de manera urgente. Por supuesto, son muchísimas las invitaciones que recibe el escritor tras su llegada ${ }^{21}$, pero ésta es sin duda una de extrema relevancia para su agente, Colonel W. F. Morse. El 5 de enero de 1982, pese al cansancio acumulado tras un decepcionante viaje transatlántico, y después de haberles pedido a los periodistas que lo dejaran descansar por un día, el dandi acude al local número 87 de Union Square. En esta dirección se encuentra el estudio fotográfico de Napoleon Sarony quien ya para el momento ha fotografiado a figuras como el escritor Walt Whitman (1878), el político Henry Ward Beecher (1875) el arquitecto Calvert Vaux (1879) o la actriz francesa Sarah Bernhardt (1880); siendo por lo tanto el fotógrafo de figuras públicas más importante del país. Como apunté, la premura de la cita de Wilde se debe a la ausencia de fotografías del escritor y, pese al mito visual que acompaña a Wilde a los Estados Unidos, a la carencia de fotografías de escritor. Por lo tanto, dado el revuelo causado por la llegada de Wilde, Morse necesita que el dandi pase por una sesión fotográfica. La circulación visual de Wilde es tan importante como su propia presencia. 


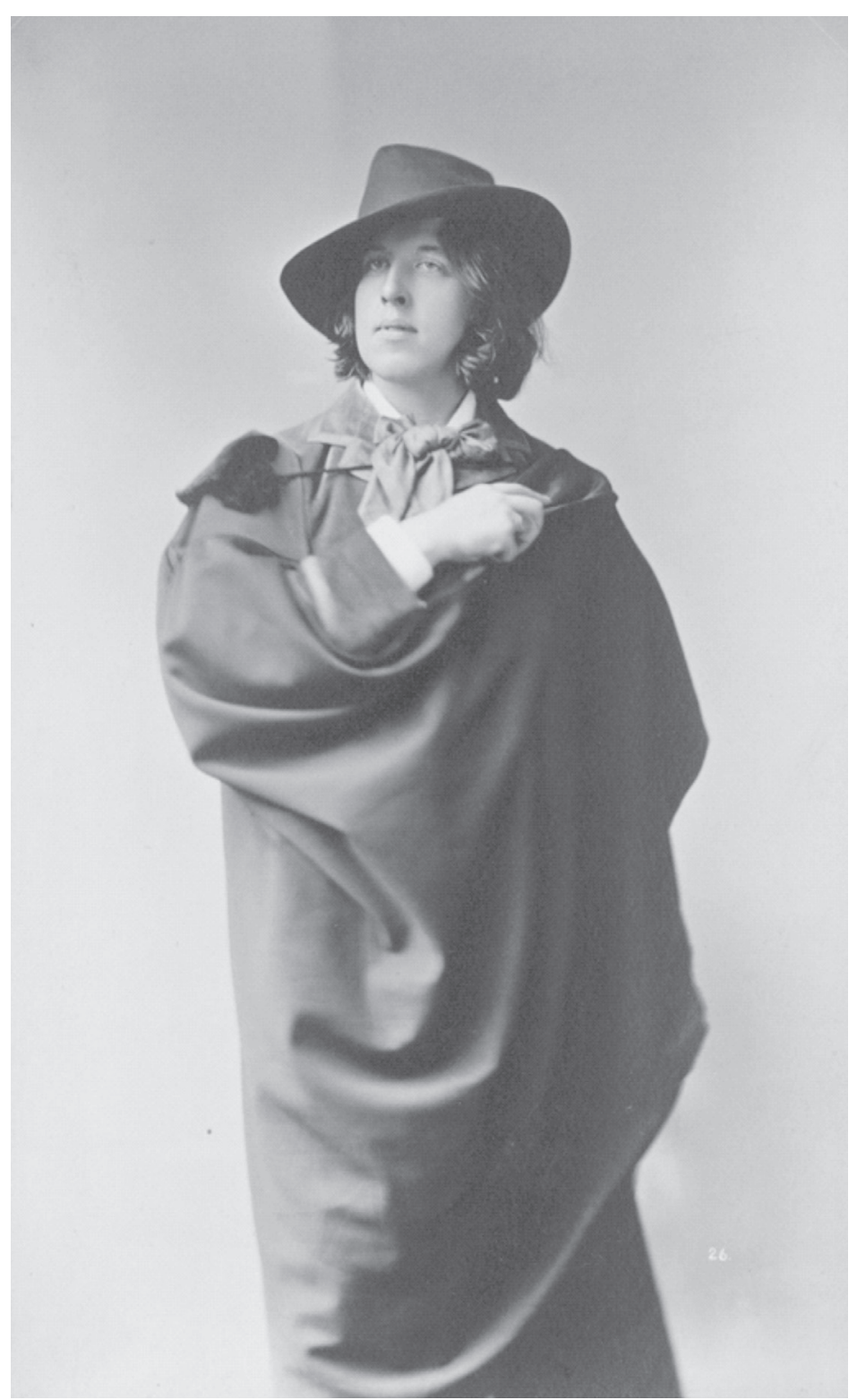

Fig. 3. Oscar Wilde, fotografía en blanco y negro de Napoleon Sarony, Nueva York, 1882. Library of Congress.

Ese día, el estudio de Sarony toma 27 fotos de Wilde en diferentes poses, atuendos y escenografías (Fig. 3). Pocos detalles se conocen acerca de lo que, asumo, debe haber sido una extensa sesión ya que no es hasta 1888, cuando Eastman lanza la cámara Kodak y el carrete de película fotográfica que sustituye a las menos prácticas placas de vidrio. Por su parte, Wilde no escribe sobre Sarony ni su correspondencia da cuenta de la sesión fotográfica llevada a cabo en Nueva York. No obstante, aparentemente, Sarony no dispara la cámara. Aunque el muy concurrido estudio fotográfico esté repleto de técnicos y asistentes, Sarony parece ser el único con acceso a la sala de operaciones ${ }^{22}$. Para el momento, los estudios neoyorkinos suelen pagar altas sumas de dinero por fotografiar
22. Así lo describe Richard G. White en un artículo especial sobre el estudio de Sarony:"These observations we make in the exhibition room, where Mr. Sarony's business partner, Mr. Campbell, presides, as he does in every other part of the establishment except the operating room, where Sarony himself is absolute. For a great photographic establishment is a complicated affair, with many assistants mechanical and artistic, and must be directed with system and administrative ability. Mar. Sarony could not do so much work, or do it so well, were it not that he is relieved of this detail, and that another hand runs the machine for which he supplies the steam". WHITE, Richard Grant. "A Morning at Sarony's," Galaxy, 1870, p. 409. 
23. HOLLAND, Merlin and Ruper Hart-Evans. The Complete Letters of Oscar Wilde, 2000, p. 64. a celebridades y, por lo tanto, contar con el derecho de vender sus fotografías. Sin embargo, en esta ocasión, el agente de Wilde exonera al estudio fotográfico del pago $^{23}$, gesto que resulta relevante para la discusión que plantearé más adelante y que propongo como parte significativa de la estrategia mediática del tour del escritor. Las fotografías de Oscar Wilde hechas por el estudio de Napoleon Sarony constituirán las imágenes más icónicas y fundamentales para la construcción del mito Wilde y contribuirán en cierto sentido a lo que considero una especie de renacimiento de la fotografía de autor.

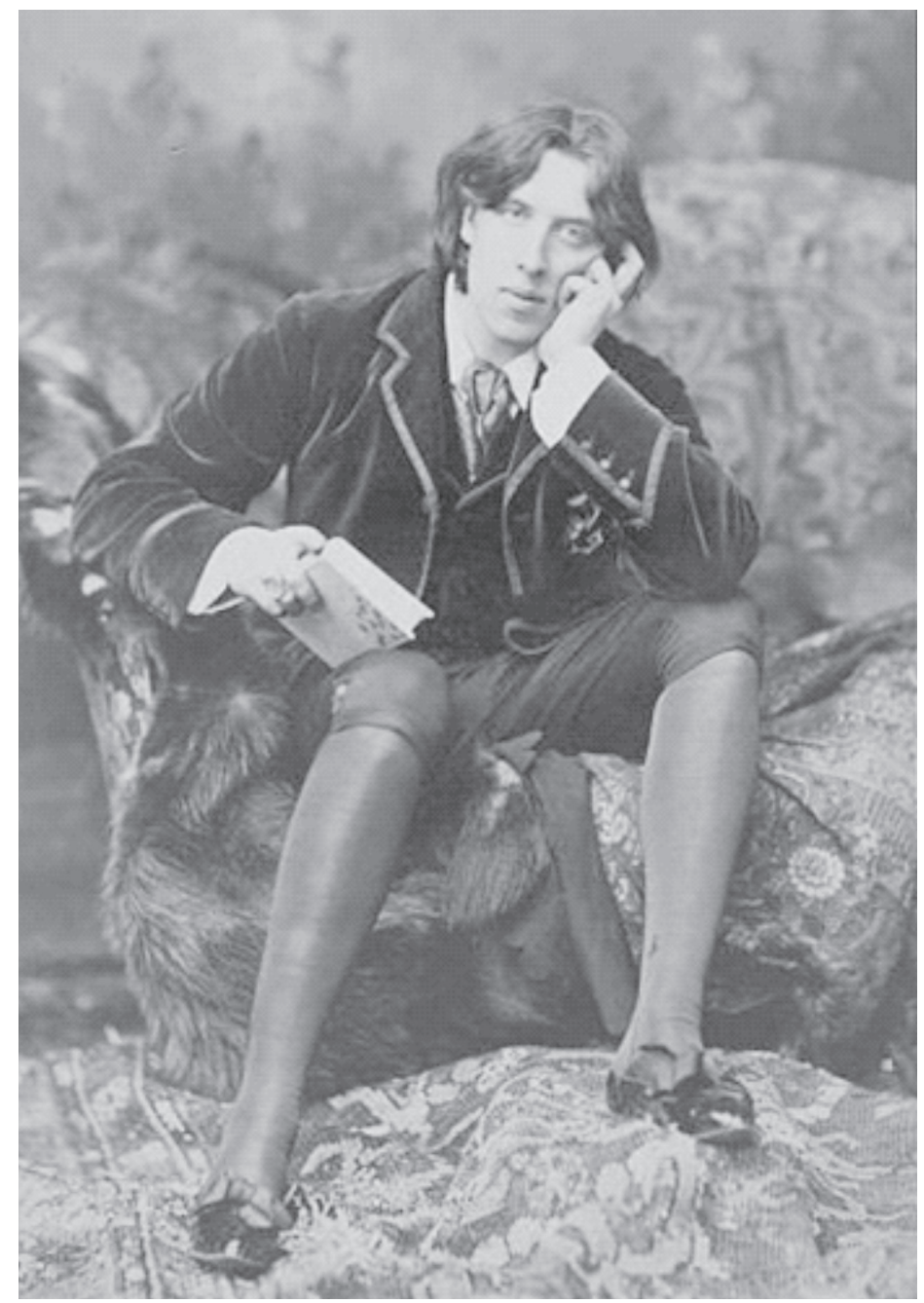

Fig. 4. “Oscar Wilde, No 18”, Oscar Wilde, fotografía en blanco y negro de Napoleon Sarony, Nueva York, 1882. Library of Congress.

Desde muy temprano, pese la inexperiencia ya citada y su escasa obra para el momento -aún no ha escrito sus obras más reconocidas-, Wilde es consciente de que su gira tiene como fin el construir a un autor. En correspondencia escrita días después de su presentación en el Chickering Hall a George Lewis, el escritor compara su éxito con el de Charles Dickens, quien 
estuviera en Nueva York: "I am sure you have pleased with my success! The Hall had an audience larger and more wonderful than even Dickens had"24. No obstante, Wilde también entiende que su construcción como autor transita por caminos distintos a los de Dickens, por ejemplo. De manera seguida, el dandi escribe: "I have several... secretaries. One writes my autographs all day for my admirers, the other receives the flowers that are left really every ten minutes. A third whose hair resembles mine is obliged to send off locks of his own hair to the myriad maidens of the city, and so is rapidly becoming bald" 25 El cabello de Wilde, al que Martí alude en ambas crónicas pero al que también la prensa llama la atención para dar cuenta de manera cifrada de una sexualidad inquietante y aberrante ${ }^{26}$, forma parte de la maquinaria de construcción del autor. Incluso, con reiteración, Wilde hace referencia a las razones financieras que también hacen posible su gira. En este sentido, el dinero cobra un papel protagónico que se verá reforzado en un proceso judicial que versará sobre la disputa de la imagen del poeta.

\section{La cita judicial}

Sin lugar a dudas, insisto, las fotografías tomadas por Sarony constituyen las imágenes más representativas de la galería visual de Oscar Wilde. A propósito de esto, en 1883, Napoleon Sarony decide demandar a la empresa Burrow-Giles Lithographic Company, por haber reproducido 85.000 copias de una de las fotografías hechas en su estudio a Oscar Wilde, foto que en el litigio cobrará el nombre de "Oscar Wilde, No 18" (Fig. 4). Este caso causa jurisprudencia ya que Sarony apela a la ley de 1865, que protege la propiedad intelectual de la fotografía y del negativo fotográfico. El 17 de marzo de 1884 se produce un pronunciamiento de la Corte Suprema que constituirá un precedente en la legislación de los derechos de propiedad fotográfica. Jane M. Gaines llama la atención sobre el hecho que de los cientos de fotografías a celebridades impresas de manera ilícita en la década de los ochenta, sea la fotografía de Oscar Wilde, a propósito de la demanda interpuesta por Sarony, la única que pueda dar cuenta de la autoría de una obra mecánica bajo la ley estadounidense de propiedad intelectual. $\mathrm{Y}$ esto tiene que ver con la muy característica corporalidad y pose de Oscar Wilde o, más bien, por el excentricismo que veía en él José Martí. El pronunciamiento de la Corte Suprema de los Estados Unidos concluye:

The third finding of facts says, in regard to the photograph in question, that it is a 'useful, new, harmonious,
24. Ibídem, p. 126.

25. Ibídem.

26. El cabello es uno de los elementos a los que se alude con mayor recurrencia para decir lo indecible; "Some of the men in Wilde's audience quite likely were gay, as newspaper reports insinuated at the time 'Many aesthetic and pallid young men in dress suits and banged hair' (i.e. bangs) were to be seen lounging at the rear of the theater when Wilde spoke for the first time in New York, one observer wrote". MORRIS, Roy Jr. Declaring His Genius: Oscar Wilde in North America, 2013, p. 31. 
27. "Burrow-Giles Lithographic Co. v. Sarony", 1884. characteristic, and graceful picture, and that plaintiff made the same... entirely from his own original mental conception, to which he gave visible form by posing the said Oscar Wilde in front of the camera, selecting and arranging the costume, draperies, and other various accessories in said photograph, arranging the subject so as to present graceful outlines, arranging and disposing the light and shade, suggesting and evoking the desired expression, and from such disposition, arrangement, or representation, made entirely by plaintiff, he produced the picture in suit.' These findings, we think, show this photograph to be an original work of art, the product of plaintiff's intellectual invention, of which plaintiff [Napoleon Sarony] is the author, and of a class of inventions for which the constitution intended that congress should secure to him the exclusive right to use, publish, and sell, as it has done by section 4952 of the Revised Statutes ${ }^{27}$.

Llama la atención que el excesivo control que describe la sentencia contraste con el laissez faire económico que parece haber prevalecido en la sesión de Nueva York. No obstante, la Corte Suprema encuentra que el argumento de la defensa de Burrow-Giles Lithographic Co. no resulta del todo descabellado ya que coincide con lo que la ley de propiedad intelectual de los Estados Unidos entiende como escritura (writing):

The constitutional question is not free from difficulty. The eighth section of the first article of the constitution is the great repository of the powers of congress, and by the eight clause of that section congress is authorized 'to promote the progress of science and useful arts, by securing, for limited times to authors and inventors the exclusive right to their respective writings and discoveries.' The argument here is that a photograph is not a writing nor the production of an author. Under the acts of congress designed to give effect to this section, the persons who are to be benefited are divided into two classes-authors and inventors ${ }^{28}$.

Pese a esto, de acuerdo con la decisión de la corte suprema y las diversas interpretaciones de este caso a propósito de la propiedad intelectual (Weil) y, en específico, de los derechos fotográficos (Gaines) han afirmado que este pronunciamiento -el cual reitera la decisión de la Circuit Cort of New York, Southern District, que ya en abril de 1883 había favorecido a Sarony-, hace equivaler fotografía y escritura. En cierto sentido, aquí se produce el nacimiento de la autoría fotográfica y, más aún, el renacimiento de la fotografía de autor. No obstante, una pregunta más parece rondar: ¿dónde parece quedar el autor fotografiado? Michael North insiste en que si bien el debate en torno a la polémica fotografía de Wilde ha producido una interesante discusión a propósito de la propiedad intelectual y la 
fotografía, ningún investigador ha insistido suficientemente en la ausencia del propio Oscar Wilde de la disputa escenificada ${ }^{29}$. Si bien, como afirma North, Oscar Wilde cede los derechos en el momento en que su agente le exime de pago a Sarony-, lo cual se registra en la sentencia: "That the plaintiff, about the month of January, 1882, under an agreement with Oscar Wilde, became and was the author, inventor, designer, and proprietor of the photograph in suit, the title of which is 'Oscar Wilde, No. 18,' being the number used to designate this particular photograph and of the negative thereof.... and that the terms 'author,' 'inventor,' and 'designer,' as used in the art of photography and in the complaint, mean the person who so produced the photograph"', su aporte en la fotografía está totalmente ausente. Por lo tanto, si bien la resolución da cuenta de la dimensión aurática de la foto -ya que tal como ha propuesto Weil, la Corte suprema se niega a pronunciarse sobre la posibilidad de que toda fotografía sea susceptible a serle aplicada el copyright ${ }^{30}$ - y entonces se produce el renacimiento de la fotografía de autor; me pregunto: ¿dónde queda parado ya no el autor de la fotografía sino el autor en la fotografía? La lectura de Michael North propone que la polémica suscitada por la comercialización de la fotografía de Wilde es un caso muy apropiado para ilustrar la complejidad de la problemática que la reproducción mecánica produce en el mundo del arte ${ }^{31}$. Más bien, me interesa plantear que la fotografía, en contraste con las ilustraciones e incluso el dictado de la Corte Suprema en cuya descripción convierte a Oscar Wilde, el autor fotografiado, en un modelo sin agencia, se vuelve un medio sobre el que se impone una materialidad lumínica con el que muchos escritores excéntricos, raros, maricones -casi todas las imágenes con las que Molloy produce su lista introductoria- se hacen tocar. Es como si la fotografía tuviera la capacidad de convertirse en una piel luminosa que no solo opera sobre la materialidad de autor sino que también fuera capaz de responder a esos ojos lujuriosos que la ven. Por lo tanto, esta nueva especie de escritor, incluso el propio Oscar Wilde, no parece quedar fuera de la cita.

\section{La política de la cita}

Ya mencioné que José Martí protesta ante lo que considera una caricaturización de Oscar Wilde por parte de la prensa estadounidense, la cual pasivamente sigue a la prensa amarillista británica en su condena (visual) de Wilde. La primera crónica de Martí sobre el apóstol del estetismo prosigue y enseguida, tras lo que ya he relatado, se centra en la inferioridad cultural de Estados Unidos:
29. NORTH, Michael. "The Picture of Oscar Wilde". PMLA, 2010, p. 187.

30. WEIL, Arthur William. American Copyright Law, 1917, p. 29.

31. NORTH, Michael. "The Picture of Oscar Wilde". PMLA, 2010, p. 190. 
32. MARTÍ, José. “El proceso de Guiteau. El estetismo. ¡Pálido Postlethwaite! El poeta Oscar Wilde. Los inmigrantes. Un grande anciano muerto". La Opinión Nacional, 1882, p. 1.
Hay en estos Estados Unidos, a la par que un ansia ávida de mejoramiento artístico, un espíritu de mofa que se place en escarnecer, como en venganza de su actual inferioridad, a toda persona o acontecimiento que demande su juicio, $y$ dé en sus manos. Y pasa en eso lo que en las ciudades de segundo orden con los dramas aplaudidos en las capitales, que solo por venir sancionados de la gran ciudad son recibidos en la provincia con mohines y desdenes, como para denotar mayor cultura y más exquisito gusto que el de los críticos metropolitanos. En esta dependencia de Europa viven los Estado Unidos en letras y artes; y como rico nuevo a quien nada parece bien para aderezar su mesa, y alhajar su casa, hacen profesión de desdeñosos y descontentadizos, y censuran con aires magistrales aquello mismo que envidian y se dan prisa a copiar ${ }^{32}$.

Pero de la crónica de Martí, que aparte de dar cuenta de la dependencia europea de Estados Unidos y, aunque de manera cifrada, sugerir la ignorancia que supone despreciar a Wilde, me interesa señalar su estructura. Quiero explorar cómo la estructura de esta crónica propone, quizá de manera involuntaria, cierto gesto esgrimido en la condena de Martí de la caricaturización de Wilde a cargo de los ilustradores británicos y estadounidenses. Por lo tanto, plantearé una lectura que tome en cuenta el gesto integral de Martí.

Como ya señalé, las cartas de Nueva York se organizan en torno a diversos temas que suceden en la metrópolis durante la estancia del intelectual cubano. La crónica en cuestión, la del 21 de enero de 1882, comienza con un breve párrafo acerca del proceso de Charles Guiteau, quien poco después será condenado a la pena capital por el asesinato del presidente Garfield. Inmediatamente, luego de un breve párrafo, Martí se refiere a la llegada de Wilde para luego hablar de la inmigración y del secreto de la prosperidad de los Estados Unido al haberle abierto los brazos. Martí incluso plantea que la Estatua de la Libertad que le regala Francia a los Estados Unidos debería tener los brazos abiertos. No obstante, el final de la crónica, Martí se refiere a la muerte de un "grande anciano":

¡A Ahora acaba de huir la vida de una mano que ha arrancado muchos secretos a la naturaleza! Fue también mano inglesa, y sostuvo una de las plumas más investigadoras y elocuentes de su tiempo. Fijó la faz humana en el cristal, y vio, como si fuese de cristal, en el cuerpo humano. El profesor [John W.] Draper ha muerto... Pueblan hoy los fotógrafos la tierra, y todos ellos deben su arte y bienestar al profesor Draper, que enamorado de las copias de estatuas y edificios que hacía en Francia Daguerre, y que su amigo Morse le trajo de París, se dio a ahondar en el descubrimiento, hasta que fijó en la lámina fotográfica el rostro de su ayudante, que fue el primer hombre cuya faz reprodujese la fotografía. En manos de Draper, fue a poco anticuado el antiguo 
procedimiento: él, como Daguerre, sometía la lámina de plata al vapor de íodina, dejaba que la luz imprimiese en la lámina la imagen, y desenvolvía gradualmente la imagen al vapor del mercurio. Él, con el bromino mejoró el hallazgo y lo reformó a tal punto que, alegres como Arquímedes, abrieron en dos habitaciones un tanto lóbregas la primera fotografía, Morse, que estaba entonces inventando el telégrafo, y Draper que no había escrito aún su revolucionario y creador Tratado de fisiología... ${ }^{33}$.

José Martí finaliza su crónica en la que destaca el comienzo de la gira de Wilde y critica su transformación en caricatura, con la muerte de Jonh W. Draper, conocido por ser el primer productor de un retrato fotográfico. La muerte de Draper coincide con la llegada de Wilde a Estados Unidos pero, más allá del azar, me interesa poner en perspectiva este artefacto, ¿a qué manos parece sugerir Martí pasara el cuerpo de Oscar Wilde? En cierto sentido, la crónica de Martí parece sugerir la inminencia de la fotografía. Martí entiende perfectamente cómo las ilustraciones encadenan a Wilde $-\mathrm{y}$ así a otros escritores raros, excéntricos, vulgares del fin de siglo- a manos que trazan su mirada fóbica. La tensión que quizá involuntariamente produce la crónica da cuenta de la posibilidad o, más bien, de la capacidad de la fotografía de convertirse en vehículo para otras sensibilidades. En cierto sentido, no solo la pose parece estar en disputa, ya que ésta constituye el principal ingrediente de las ilustraciones sensacionalistas (aunque por supuesto, aún más desfigurada por ojos y manos ponzoñosas). La fotografía de autor parece ofrecerles a estas sensibilidades la capacidad de hacer de sus cuerpos el gran mito de autor. Escritores y artistas como Salvador Novo, Gabriela Mistral, Augusto D'Halmar, Delmira Agustini, Armando Reverón, Frida Kahlo y más tarde, Alejandra Pizarnik, Clarice Lispector, Reinaldo Arenas, Severo Sarduy, Pedro Lemebel, Mario Bellatin, hacen de la materialidad fotográfica una dimensión relevante y hasta definitiva para su contextura de autor.

Dadas las razones antes expuestas, dudo de que José Martí haya asistido a la cita neoyorkina con Wilde. No obstante, lo que queda claro es que Martí nunca se acerca al puerto en el que desembarca Oscar Wilde. ¿De dónde proviene entonces la cita que hace Martí de Wilde? ¿De dónde parte la descripción de "ese hombre joven y fornido, de elegante apostura, de enérgico rostro, abundante cabello castaño, que se escapa de su gorra de piel sobre el Ulster recio que ampara del frío su robusto cuerpo"34? Martí parece citar a ciegas el cuerpo de Wilde o más bien, cita aquel cuerpo que reporteros y cronistas ven llegar, cita lo que esas manos dicen que vieron e incluso cita las ilustraciones que de Inglaterra llegan a los Estados Unidos. Es decir, Martí cita la horrorosa fascinación de ver a Oscar Wilde.
33. MARTÍ, José. "El proceso de Guiteau. El estetismo. ¡Pálido Postlethwaite! El poeta Oscar Wilde. Los inmigrantes. Un grande anciano muerto". La Opinión Nacional, 1882, p. 1.
34. MARTÍ, José. “El proceso de Guiteau. El estetismo. ¡Pálido Postlethwaite! El poeta Oscar Wilde. Los inmigrantes. Un grande anciano muerto". La Opinión Nacional, 1882, p. 1. 
35. MALABOU, Catherine. La plasticidad en espera, 2013, p. 94.
La espectacularidad fotográfica, es decir, su exhibicionismo le ofrece al nuevo escritor la posibilidad de que otros testifiquen la transformación de su corporalidad. En cierto sentido, la fotografía de autor hace del cuerpo un proyecto en proceso que definitivamente devuelve a los ojos extraños. La pose, insisto, es entonces un solo elemento que de por sí no está limitada a la foto. Por el contrario, la fotografía tiene la capacidad de entenderse como cuerpo autoral, como radical sustituto del autor, y por lo tanto, es capaz de ser tocada. En este aspecto, aquí se activa la manera en que la filósofa francesa Catherine Malabou entiende la filosofía de Hegel como reemplazamiento. Es decir, la forma, no se forma más que como posibilidad de ser reemplazada. Malabou dice que ésta, la forma, sólo tendría identidad si es reemplazable, sustituible, relevable ${ }^{35}$.

La piel de la foto se torna piel de escritor. Citar la foto no es solo citar al autor sino citar su autoría. La política de la cita cobra entonces relevancia. Como antes afirmé, Martí cita a ciegas pero al hacerlo se da cuenta y propone una crítica pese a los tiempos de corbata negra y al no vestirse como lo hace Oscar Wilde.

\section{Casa de citas}

Finalizo este artículo con una cita más, una cita fuera de contexto. Esta vez, cito un recuerdo personal que publica Sylvia Molloy acerca de la poeta argentina Alejandra Pizarnik:

Alejandra es, por excelencia, el lector con el libro en la mano: pose primordial de todo escritor, aquí se vuelve explícita, ejemplar. No bien despierta, y como un deber que acepta gozosamente, un ejercicio a la vez espiritual y profesional, Alejandra lee, Alejandra escribe, Alejandra acumula citas: son tres fases de una misma actividad que necesita la mirada del otro. No sé si en aquella ocasión sabría que yo la miraba: el detalle biográfico no tiene importancia, sí lo tiene el gesto exhibicionista. Basta recorrer sus diarios para ver con qué cuidado analiza su lectura, anota lo que le impresiona, establece comparaciones: en suma, con qué cuidado o más bien pasión, elabora lo que lee, como quien lo prepara -lo adereza, diría- para un uso ulterior. El diario de Pizarnik reflexiona, cuestiona, y sobre todo cita textos que va juntando al azar, como quien almacena material que puede ser útil en un futuro: para componer su imagen, para asentar su escritura. Imposible determinar un itinerario de lectura, las citas se acumulan aparentemente al azar: "Quiero morirme siendo, siendo ayer", cita de Asíque pasen cinco años de Lorca, alterna con "la garúa de la ausencia", cita del tango Ventanita de arrabal; una alusión a Georges Schéhadé alterna, a su vez, con una cita de Mi noche triste. 
Así, desjerarquizándolas, restituyéndolas a la pura letra, Pizarnik en su diario recicla citas y referencias, acaso para usarlas después, como objets trouvés, para ir componiendo lo que llama su Casa de citas: archivo literario, materia misma de una autofiguración que permanentemente necesita testigos $^{36}$.

Aunque no tengo mayor duda de que Sylvia Molloy ve a Pizarnik, en este pasaje no solo Sylvia Molloy parece citar una fotografía, aquella en la que la poeta fuma mientras lee un libro que sostiene con una de sus manos, sino que de su ejercicio podría inferirse que la fotografía de autor, la fotografía de estos autores, también puede entenderse como autofiguración basada en desjerarquizaciones, que necesita de testigos y que en cierto sentido se presenta como objet trouvé. José Martí pone en escena la relevancia de la visualidad de autor. Sylvia Molloy entiende lo que significa para Martí la lujuria de ver a Oscar Wilde. Con esta casa de citas que despliega Martí, quien cita la llegada de Wilde, la muerte de Draper, la maliciosa mano de Du Maurier y, a la vez, cita a Wilde; la fotografía parece irrumpir como ensayo y repetición para una autonomía material. La capacidad exhibicionista de estas fotos, que pasan de mano en mano, de cita en cita, producen una sustitución. La crítica del caso jurídico, que aparentemente deja de lado a Wilde o lo convierte en una figura sobre la que se discierne el copyright de la fotografía o la inherencia de la reproductibilidad mecánica sobre el arte, ha ignorado la piel luminosa que la fotografía de autor concede a estos escritores, aquella que José Martí parece entender cuando en Nueva York cita a ciegas a Oscar Wilde.
36. "Una torpe estatuilla de barro: figuración de Alejandra Pizarnik". Taller de Letras, 2015, p. 73. 


\section{Referências}

"Burrow-Giles Lithographic Co. v. Sarony", 111 U.S. 53, 4 S, Ct. 279, 1884.

"City Summary". New York Clipper. Vol. XXIX, n. 43, p. 710, 14/01/1882.

GAINES, Jane M. Contested Culture: The Image, the Voice, and the Law. Chapel Hill: University of California Press, 1991.

HOFER, Matthew; SCHARNHORST, Gary (eds). Oscar Wilde in America: The Interviews. Urbana and Chicago: University of Illinois Press, 2010.

HOLLAND, Merlin ; HART-EVANS, Ruper. The Complete Letters of Oscar Wilde. New York: Henry Holt and Co., 2000.

MALABOU, Catherine. La plasticidad en espera. Santiago de Chile: Palinodia, 2013.

MARTÍ, José. Obras completas: (edición crítica) Tomo 9 (1881-1882) Estados Unidos. La Habana: Centro de Estudios Martianos, 2000. $11 / 02 / 1882$.

. "Oscar Wilde". La Opinión Nacional. Caracas, p. 1, . "El proceso de Guiteau. El estetismo. ¡Pálido Postlethwaite! El poeta Oscar Wilde. Los inmigrantes. Un grande anciano muerto". La Opinión Nacional. Caracas, p. 1, 21/01/1882.

MOLLOY, Sylvia. "La política de la pose". Las culturas de fin de siglo en América Latina. Josefina Ludmer (ed.). Rosario: Beatriz Viterbo, 1994, p. 128-138.

- Poses de fin de siglo. Desbordes del género en la modernidad.

Buenos Aires: Eterna Cadencia, 2012.

. "Una torpe estatuilla de barro: figuración de

Alejandra Pizarnik”. Taller de Letras. n. 57, p. 71-79, 2015.

MORRIS, Roy Jr. Declaring His Genius: Oscar Wilde in North America. Cambridge: Harvard University Press, 2013.

NAST, Thomas. "Oscar Wilde on Our Cast-Iron Stover". Harper's Weekly. p. 575, 9 de septiembre de 1882.

NORTH, Michael. “The Picture of Oscar Wilde”. PMLA. vol. 125, n. 1, p. 185-191, enero de 2010.

“Oscar Wilde on the Platform." The National Police Gazette. 
New York, p. 4, 28/01/1882.

"Oscar Wilde's Lecture: A Large Audience Listens to the Young Aesthete." The New York Times. New York, p. 5, 10/01/1882.

SISKIND, Mariano. Cosmopolitan Desires: Global Modernity and World Literature in Latin America. Chicago: Northwestern University Press, 2014.

WEIL, Arthur William. American Copyright Law. Chicago: Callaghan, 1917.

WHITE, Richard Grant. "A Morning at Sarony's," Galaxy. Vol. 9, p. 409, March 1870.

ZAMBRANO, Gregory. "La Sección constante de José

Martí. Pequeño tratado de enciclopedia”. Revista Investigación.

Universidad de los Andes, p. 56-57, 2004. 
